\title{
Effect of Physical Activity on Pain and Functional Abilities in Patients with Rheumatoid Arthritis at an Autoimmune Clinic in Accra, Ghana
}

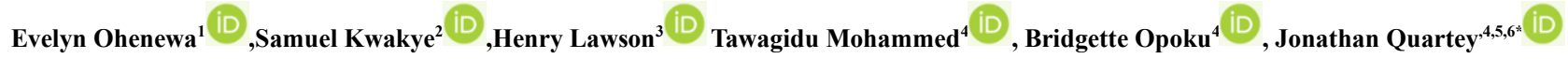 \\ ${ }^{1}$ Physiotherapy Department, University of Ghana Medical Centre, Accra, Ghana. ${ }^{2}$ West Africa Football Academy, Sogakope, Ghana. \\ ${ }^{3}$ Department of Community Health, University of Ghana Medical School, College of Health Sciences, University of Ghana ${ }^{4}$ Department of \\ Physiotherapy, School of Biomedical and Allied Health Sciences, College of Health Sciences, University of Ghana, Accra, Ghana. ${ }^{5}$ School of \\ Health Professions Education, Faculty of Health, Medicine and Life Sciences, Maastricht University, Netherlands. ${ }^{6}$ Centre for Sport, \\ Exercise and Osteoarthritis Research Versus Arthritis, UK.
}

*Corresponding author: neeayree@googlemail.com

\section{Abstract}

To cite: Ohenewa-Sarpong E, Kwakye S, Lawson H, Mohammed T, Opoku B, Quartey J,. Effect of Physical Activity on Pain and Functional Abilities in Patients with Rheumatoid Arthritis at an Autoimmune clinic in Accra, Ghana. JPRM 2021.3(2) 2: 85-91. doi: 10.21617/jprm2021.3214

Background: Rheumatoid arthritis is a chronic systemic disease that affects the joints, connective tissues, tendons, and fibrous tissues. Despite early interventions, there is significant activity limitation due to moderate and high pain intensities in majority of affected individuals.

The study set out to determine the effect of physical activity on pain and functional ability among rheumatoid arthritis patients. Methods: A pre-test, post-test quasi experimental study conducted among 60 rheumatoid arthritis patients (divided into intervention and control groups) were recruited from the Autoimmune clinic of Korle Bu Teaching Hospital for this quasiexperimental study. The international physical activity questionnaire, multidimensional health assessment questionnaire and numerical pain rating scale were used to obtain data. Pedometers and a stationary cycle were used for physical activity (intervention). Paired $t$-test was used to compare outcomes between the level of physical activity in relation to pain and functional ability and outcomes between pre and post functional abilities at a 0.05 level of significance.

Results: Majority $24(80.0 \%)$ of participants from the intervention group reported low, while $6(20.0 \%)$ reported moderate physical activity levels. Thirteen (43.4\%) and $10(33.3 \%)$ participants from the intervention and control groups reported moderate pain on NPRS before intervention, which reduced to 7 (23.3\%) in the intervention group, as compared to $9(30 \%)$ in the control group. There was a significant difference $(\mathrm{p}<0.05)$ for functional ability among the intervention group before and after the intervention programmes but no significant differences $(\mathrm{p}>0.05)$ for most domains of functional ability except health concern $(\mathrm{p}=0.034)$ among the control group.

Conclusion: Patients with RA have a relatively low physical activity level but benefit significantly from a moderate intensity aerobic exercises such as cycling and walking by improving pain levels, functional ability and general health. Clinicians should promote and encourage patients with RA to engage in physical and recreational activities.

Keywords: Rheumatoid arthritis, physical activity, pain, functional abilities 


\section{INTRODUCTION}

Rheumatoid arthritis (RA) is a chronic systemic disease that affects the joints, connective tissues, tendons, and fibrous tissues [1]. It tends to strike during the most productive years of adulthood, between the ages of 20 and 40, and is a chronic disabling condition which often causes pain and deformity [1]. Rheumatoid arthritis is one of the leading causes of disability worldwide [2]. Deterioration in physical function is an important component of RA outcomes, with prevention of future disability being an essential goal of treatment [3]. Despite early interventions, pain intensity remains moderate to high in majority of those affected, leading to activity limitations and participation restrictions [4].

According to Vollenhoven [5] the susceptibility of women than men to rheumatoid arthritis is not clear, nevertheless genetic (X linked) factors and or hormonal features are probably involved. Generally, physical activity levels, has been shown to reduce with age $[6,7]$. Cooney et al [8] reported that the symptoms of the disease such as pain and fatigue, resulted in decreased functional ability and physical activity. Hernández-Hernández et al [9] indicated that the number of minutes of moderate and vigorous activity per day, as evaluated by accelerometery, showed significantly lower physical activity levels in RA patients than in healthy controls. However, physical activity is said to increase the health-related quality of life in people with RA since exercise of physical activity which helps in the production of endorphins which helps in the positive feelings and reduce the perception of pain. Also exercises decreases the risk of various conditions such as cardiovascular disease and osteoporosis [10] while findings of a randomized controlled trial by Lemmey et al [11] indicate that exercise is considered to be fundamentally beneficial for RA patients. People with RA tend to get tired easily. Fatigue can significantly impact on the quality of life and functioning of people with RA [12]. Increasing physical activity by walking has significant effects on fatigue and other RA symptoms [13]. The reported benefits of properly designed physical exercise programmes include improved cardiorespiratory fitness and health, increased muscle mass, reduced adiposity (including attenuated trunk fat), improved strength, and physical functioning, all achieved without exacerbation of disease activity or joint damage. Physical activity also has various disease-specific benefits such as improved functional ability and reduction of pain population in patients with RA [14]. Specifically, physical activity may improve bone mineral density at the femoral neck, slow radiographic disease progression at the small joints, slow the development of atherosclerosis and diminish disease activity in general [15]. A relatively low physical activity level before the onset of RA is associated with greater disease severity. For instance, a study conducted in Sweden, found that patients engaging in regular physical activity, at least 30 minutes, three times a week for 5 years before the diagnosis of RA had significantly lower Disease Activity Score determined on 28 joints (DAS 28) and Health Assessment Questionnaire (HAQ) values [16]. Other studies suggest that physical activity may even protect against RA development [17 \& 18]. This shows that the level of physical activity has major implications both before and during the disease, RA [19]. Regular physical activity and exercise by patients with RA has numerous health benefits, nevertheless, the majority of patients with RA are physically inactive [20], however, it is believed that less physical activity can rather increase their pain and affect their general function [4], therefore there is a need to enhance the physical activity levels of RA patients. A randomised controlled trial study, showed that a two-year high-intensity exercise program of combined aerobic and strength training significantly improved functional ability of the exercising patients with RA as against nonexercising RA controls [21]. A 2010 metaanalysis of randomised controlled trials also concluded that resistance exercise training can improve different strength outcomes such as isokinetic, isometric and grip strength among people with RA [22].

Studies on RA conducted in few African countries showed an increasing prevalence and severity in urban populations, though not that many studies on RA have been conducted in Africa [2]. Recent research highlights the salient role of modifiable behaviours such as physical inactivity on various aspects of the immune system and autoimmune diseases [23]. There is strong evidence that when healthcare practitioners incorporate physical activity advice in their clinical practice, they can significantly contribute towards altering behaviours and help patients with other chronic non-communicable diseases to become more physically active [24]. Physically active RA patients have been found to have a milder disease course, better cardiovascular disease (CVD) profile, and improved joint mobility. In spite of this positive outcomes, a general trend observed is that patients with autoimmune diseases tend to be less physically active as compared to the general population [23]. Hence the aim of this study was to determine the 
effect of physical activity on pain and functional ability among patients with rheumatoid arthritis.

\section{METHODS AND MATERIALS}

This study was a pre-test, post-test quasi experimental study conducted at the autoimmune clinic of the Korle $\mathrm{Bu}$ Teaching Hospital in Accra, Ghana. The experiment was conducted among patients with RA about the effect physical activity has on their pain and functional ability. Pre-test baseline included measuring the physical activity and pain levels of patients with RA. After implementing the intervention, pain levels and functional abilities were measured again. A convenient sampling method was used to recruit participants for the study because they were readily available at the autoimmune clinic and participation in the study depended on willingness of patients. A sample size of 60 was determined using the Taro Yamane formula [25]: $\mathrm{n}=\mathrm{N} /[1+\mathrm{N}$ (e) 2]. Participants for this study included rheumatoid arthritis patients between the ages of 18 to 65 years. Most of the patients had RA affecting mostly the lower limb joints, hence the focus. Patients with other autoimmune diseases like lupus, psoriasis, crohns and diabetes insipidus, were excluded from this study. The International Physical Activity Questionnaire (IPAQ) used in determining physical activity levels, Numerical Pain Rating Scale (NPRS) for level of pain and Modified Health Assessment Questionnaire (MD-HAQ) for functional abilities were used to obtain data from the participants while a pedometer and stationary cycle were used for an intervention programme. A data capturing form was used to obtain demographic information from participants. A data capturing form was used to obtain demographic information from participants.
Ethical
clearance
(SBAHS-

PH./10514985/SA/2017-2018) was sought and obtained from the Ethics and Protocol Review Committee of the School of Biomedical and Allied Health Sciences, University of Ghana. The researchers explained the purpose of the study and obtained consent before participants were recruited into the study. Participants were requested to pick without replacing a sealed paper labelled either A or B which was used to randomly assign them into two groups; A (intervention) and B (control). Group A comprised of participants who received monitored modified physical activity programmes, (cycling and walking for twice a week for three weeks) by a physiotherapist in addition to their regular treatment package prescribed by the physician. The modified physical activity programme which was moderate intensity aerobic exercises consisted of walking with a minimum target of 3000 steps daily and stationary cycling for 5 minutes, twice every week for three weeks. Participants were given pedometers, which were worn daily to record the number of steps taken every day before they go to bed at night. Weekly records of number of steps were taken from participants and recorded by the researchers to track the adherence of participants to regimen. None of the participants had to stop the intervention process due to disease exacerbation.

Group B comprised of participants who received only their regular treatment package prescribed by the physician. The same exercise regimen was conducted for participants in the control group after data was obtained from the intervention group. The IPAQ and MD-HAQ which takes about 25 minutes to complete were administered and retrieved by the researchers before and after the intervention while the numerical pain rating scale was used to evaluate the levels of pain in these patients before and after the intervention. Patients were monitored by a rheumatologist at the autoimmune clinic during the intervention phase. Participants in the control group were encouraged to continue taking their medication and visit the clinic for their usual treatment. Data collection commenced in April 2018 and was concluded in August 2018.

\section{Data Analysis}

Statistical Package for Social Sciences (SPSS) version 23 was used to analyse the data. Descriptive statistics were used to summarize the demographic data obtained. Paired t-test was used to compare outcomes between the level of physical activity in relation to pain and functional ability and for outcomes between pre and post functional abilities for each group. Mann-Whitney $U$ test was used to determine the relationship of pedometer readings (steps) between age groups, sex and marital status of participants. Statistical significance was set at 0.05 . 


\section{RESULTS}

A total of 60 Rheumatoid arthritis patient were recruited for this study of which equal numbers (30) of participants were randomly distributed into the control and intervention group. Majority $24(80.0 \%)$ of participants from the intervention group were females, $19(63.3 \%)$ were married while $11(36.7 \%)$ were in the age range 41-50 years. The distribution of sex, marital status and age for both groups are presented in (Table 1). Majority 21 (70.0\%) of the control and $24(80.0 \%)$ intervention groups reported low physical activity levels while $9(30.0 \%)$ of the control and $6(20.0 \%)$ intervention groups reported moderate physical activity levels. Thirteen (43.4\%) participants from the intervention group and $10(33.3 \%)$ from the control group scored $6 / 10$ on the numerical pain rating scale (NPRS) indicating a moderate pain level before the implementation of the intervention programme, which reduced to 7 $(23.3 \%)$ in the intervention group, as compared to $9(30 \%)$ in the control group.

Table 1: Demographic characteristics of 60 patients with RA from the autoimmune clinic)

\begin{tabular}{lllll}
\hline Demography & $\begin{array}{l}\text { Control Group } \\
\text { Frequency } n=30\end{array}$ & Percent (\%) & $\begin{array}{l}\text { Intervention Group } \\
\text { Frequency } n=30\end{array}$ & Percent (\%) \\
\hline Sex & & 13.3 & & \\
Male & 4 & 86.7 & 6 & 80.0 \\
$\begin{array}{l}\text { Female } \\
\text { Marital status }\end{array}$ & 26 & & 24 & \\
$\begin{array}{l}\text { Single } \\
\text { Married }\end{array}$ & 9 & 30.0 & 11 & 36.7 \\
Age & 21 & 70.0 & 19 & 63.3 \\
$18-30$ & 4 & 13.3 & 4 & \\
$31-40$ & 11 & 36.7 & 9 & 30.3 \\
$41-50$ & 8 & 26.7 & 11 & 36.7 \\
$51-60$ & 5 & 16.7 & 3 & 10.0 \\
$60+$ & 2 & 6.7 & 3 & 10.0 \\
\hline
\end{tabular}

Significant differences were found in the control and intervention groups for general health $(\mathrm{p}=$ $0.029)$ and fatigue $(\mathrm{p}=0.044)$ domains before intervention and no significant differences $(\mathrm{p}>$ 0.05 ) in the other domains as shown in Table 2. There was a significant difference before and after the intervention programme for all domains $(\mathrm{p}<$ 0.05 ) of functional abilities in the intervention group and for only general health concern $(\mathrm{p}=$ 0.034 ) before and after in the control group as shown in Table 3.

Table 2: Baseline Characteristics of the participants $(n=60)$

\begin{tabular}{lllll}
\hline MHAQ domain & $\begin{array}{l}\text { Control } \\
\text { Mean } \pm \text { SD }\end{array}$ & $\begin{array}{l}\text { Intervention } \\
\text { Mean } \pm \text { SD }\end{array}$ & T & Sig. \\
\hline Daily Activity & $10.53 \pm 4.45$ & $11.67 \pm 3.63$ & 1.080 & 0.285 \\
Psychological Status & $1.83 \pm 1.64$ & $2.13 \pm 1,46$ & 0.749 & 0.457 \\
Pain & $5.23 \pm 1.43$ & $5.80 \pm 1.43$ & 1.538 & 0.130 \\
General health & $3.30 \pm 0.59$ & $3.63 \pm 0.56$ & 2.240 & $0.029^{\star}$ \\
Fatigue & $5.03 \pm 1.29$ & $5.77 \pm 1.45$ & 2.059 & $0.044^{*}$ \\
Health concern & $4.56 \pm 1.25$ & $5.10 \pm 1.12$ & 1.373 & 0.088 \\
\hline * & & & &
\end{tabular}


Table 3: Comparisons within groups before and after intervention $(n=60)$

\begin{tabular}{|c|c|c|c|c|}
\hline Group & Outcome Measure & $\begin{array}{l}\text { Pre-Intervention } \\
\text { Mean士SD }\end{array}$ & $\begin{array}{l}\text { Post-Intervention } \\
\text { Mean } \pm \text { SD }\end{array}$ & P-Value \\
\hline \multirow[t]{6}{*}{ INTERVENTION } & Daily Activity & $11.67 \pm 3.63$ & $8.20 \pm 2.75$ & $0.000^{*}$ \\
\hline & Psychological status & $2.13 \pm 1,46$ & $1.03 \pm 0.99$ & $0.000^{*}$ \\
\hline & Pain & $5.80 \pm 1.42$ & $4.67 \pm 1.24$ & $0.000^{*}$ \\
\hline & General health & $3.63 \pm 0.56$ & $2.96 \pm 0.41$ & $0.000^{*}$ \\
\hline & Fatigue & $5.70 \pm 1.45$ & $5.00 \pm 1.23$ & $0.000^{*}$ \\
\hline & Health concern & $5.10 \pm 1.12$ & $4.43 \pm 0.77$ & $0.000^{*}$ \\
\hline \multirow[t]{6}{*}{ CONTROL } & Daily Activity & $10.53 \pm 4.45$ & $10.57 \pm 4.40$ & 0.895 \\
\hline & Psychological status & $1.83 \pm 1.64$ & $1.97 \pm 1.69$ & 0.489 \\
\hline & Pain & $5.23 \pm 1.43$ & $5.23 \pm 1.47$ & 1.00 \\
\hline & General health & $3.30 \pm 0.59$ & $3.40 \pm 0.67$ & 0.264 \\
\hline & Fatigue & $5.03 \pm 1.29$ & $5.03 \pm 1.29$ & 1.00 \\
\hline & Health concern & $4.56 \pm 1.29$ & $4.77 \pm 1.30$ & $0.034^{*}$ \\
\hline
\end{tabular}

*significant at $\mathrm{p}<0.05$

There was significant difference $(\mathrm{p}<0.05)$ between the $18-40$ and above 40 years age groups of pedometer readings from week one through to three. There was also significant $(p<0.05)$ differences between males and females in the first week only of pedometer reading. There was no significant difference for marital status of pedometer readings from week one through to three as presented in (Table 4)

Table 4: Analysis of pedometer readings for the intervention group

\begin{tabular}{lllllll}
\hline Demographic & $\begin{array}{l}\text { Week 1 } \\
\text { Mean rank }\end{array}$ & Sig. & $\begin{array}{l}\text { Week 2 } \\
\text { Mean rank }\end{array}$ & Sig. & $\begin{array}{l}\text { Week 3 } \\
\text { Mean rank }\end{array}$ & Sig. \\
\hline Age & & & & & & \\
$\begin{array}{l}18-40 \\
41+\end{array}$ & 20.46 & $0.007^{*}$ & 20.38 & $0.008^{*}$ & 22.10. & $0.000^{*}$ \\
Sex & 11.71 & & 11.76 & & 10.53 & \\
$\begin{array}{l}\text { Male } \\
\text { Female }\end{array}$ & 21.83 & $0.049^{*}$ & 20.75 & 0.102 & 20.00 & 0.162 \\
Marital & 13.92 & & 14.19 & & 14.38 & \\
Single & 15.18 & 0.880 & 16.50 & 0.636 & 17.73 & 0.292 \\
Married & 15.68 & & 14.92 & & 14.21 & \\
\hline
\end{tabular}

\section{DISCUSSION}

The study revealed that majority of the participants in the control and intervention groups were females. This may be as a result of genetic (X -linked) factors and hormonal features probably involved [5], that make women more susceptibility to RA than men. Majority of the participants in both groups were married and middle aged, which also corroborates findings of WHO in 2017 [1]. In other words, this study reveals similar trends from a previous study.

The low levels of physical activity reported by many participants in both groups may be due to the disease activity which causes pain, fatigue and decreased muscle strength as a result of joint destabilization and decreased muscle mass thus causing limitation in function [8] and corroborates finding by Hernández-Hernández et al [9] who reported that the time in minutes of physical activity engaged in per day was significantly lower in rheumatoid arthritis patients than in healthy controls. This study showed that pain levels of participants in both groups did not differ before the intervention programme however, there was a significant reduction in the pain levels of the number of participants after the intervention programme. The reduction in pain may therefore be as a result of the analgesic effect of endorphins released by the body, which is stimulated by physical activities (exercise). Hurkmans et al [23] also indicated that patientreported outcome in rheumatoid arthritis are strongly influenced by pain and also alluded to the fact that moderate intensity exercises modify central pain processing and therefore reduces pain. 

Functional Abilities in Patients with Rheumatoid Arthritis at an Autoimmune clinic in Accra, Ghana.

This study revealed that, there was improvement in the functional abilities (difficulty in performing daily activities; psychological status; pain level; general health; problems with fatigue and health concerns) among participants in the intervention group and non for participants in the control group. Therefore, it could be that the observed decreased functional abilities of the participants may be due to loss of muscle mass, pain, fatigue decreased muscle strength, and immunological factors. Cooney et al [8] reported that the symptoms of RA such as pain and fatigue, resulted in such patients having decreased functional ability and physical activity. However, it may be justifiable to infer that the improvement of functional abilities among participants in the intervention group may have been achieved as a result of the physical activity. The physical activity used in this study may have facilitated the development of healthy musculoskeletal system by improving muscle strength and endurance, joint mobility as well as cardiovascular endurance [11].

Participants 41years and above in this study made the least number of steps thus classifying them as least physically active as compared to the 18-40-year olds who made the highest number of steps. It may be concluded that physical activity invariably reduces with age.

CONCLUSION

The study showed that patients with RA have a low physical activity level. Furthermore, pain levels and functional abilities of patients with RA improved after performing five minutes of cycling and walking twice for three weeks. This indicates that a moderate intensity aerobic exercise (structured physical activity) programme, could significantly benefit patients with RA. A study with larger sample size and even national distribution may be useful to affirm the findings of this study

\section{DECLARATION}

Contributors The concept and study design were developed by ES and JQ. ES, JQ, SK, were involved in data collection. SK, HL, TM and BO provided advice on statistical analysis. ES, HL, SK, TM, BO and JQ, contributed on the interpretation of results. The manuscript was written by JQ, HL and SK while ES, TM and $\mathrm{BO}$ provided substantial amounts of references. ES, HL, SK, TM, BO and JQ, contributed towards the draft and approved the final manuscript.

Competing interests There were no competing interests from all authors in this study.

Ethics approval Ethical clearance (SBAHSPH./10514985/SA/2017-2018) was obtained from the Ethics and Protocol Review Committee of the School of Biomedical and Allied Health Sciences, University of Ghana. An introductory letter was obtained from
Department of Physiotherapy to the Ethics and Review Committee of the Korle-Bu Teaching Hospital for approval to proceed with the study. The necessary permissions were sought and obtained from participants who signed an informed consent form.

Acknowledgements Special thanks go to the patients recruited from the Autoimmune clinic of Korle $\mathrm{Bu}$ Teaching Hospital for their participation in this study. Appreciation also goes to the staff of the Autoimmune clinic and Physiotherapy Department of Korle $\mathrm{Bu}$ Teaching Hospital as well as the Department of Physiotherapy, School of Biomedical and Allied Health Sciences, University of Ghana for their support.

\section{REFERENCES}

1. World Health Organization. (2007). A guide for population-based approaches to increasing levels of physical activity: implementation of the WHO global strategy on diet, physical activity and health.

https://apps.who.int/iris/bitstream/handle/10665/ 43612/9789241595179_eng.pdf?sequence $=1 \& i$ sAllowed =y. Retrieved April 10, 2020 at 10:55pm

2. Ampofo, R. O., Osei-Sarpong, C., \& Botwe, B. O., (2016). Rheumatoid arthritis among autoimmune diagnosed patients: A pilot study at Africa's third largest hospital, Tropical Journal of Medical Research 2016; 19(2): 88- 93.

3. Hirata, A., Miyamura, T., Suenaga, Y., Katayama, M., Suematsu, E., \& Tohma, S. (2018). Latent psychological distress existing behind a set of assessment measures is comparable to or more important than symptoms or disability in the association with quality of life and working status of patients with rheumatoid arthritis. Modern Rheumatology, 28 (6), 968-975. https://doi.org/10.1080/14397595.2018.1428043

4. Ahlstrand I, Björk M, Thyberg I, Börsbo B, Falkmer T. Pain and daily activities in rheumatoid arthritis. Disability and Rehabilitation 2012; 34(15):1245-53.

5. Van Vollenhoven, R.F. Treatment of rheumatoid arthritis: state of the art 2009. Nature Reviews Rheumatology 2009; 5(10): 531.

6. Cameron, C., Wolfe, R., and Craig, C.L. 2007. Physical activity and sport: encouraging children to be active. Canadian Fitness and Lifestyle Research Institute, Ottawa, Ont.

7. assett D, Schneider $\mathrm{PJ}$, and Huntington G. Physical Activity in an Old Order Amish Community. Medicine and Science in Sports and Exercise. 2004, 36, (1), 79-85.

8. Cooney JK, Law R-J, Matschke V, Lemmey AB, Moore JP, Ahmad Y, Jones JG, Maddison $\mathrm{P}$, and Thom JM. Benefits of Exercise in Rheumatoid Arthritis. Journal of Aging Research. 2011; 10: 681640 .

9. Hernández-Hernández $\mathrm{V}$ and Ferraz-Amaro $\mathrm{I}$, Díaz-González F. Influence of disease activity on the physical activity of rheumatoid arthritis 
patients. Rheumatology (Oxford). 2014; 53(4): 722-731.

10. Brodin N, Hurkmans E, DiMatteo L, Nava T, Vlieland TV, Opava $\mathrm{CH}$. Promotion of health-enhancing physical activity in rheumatoid arthritis: a comparative study on healthcare providers in Italy, The Netherlands and Sweden. Rheumatology International 2015; DOI 10.1007/s00296-015-3267-4.

11. Lemmey, A. B., Marcora S. M., Chester K., Wilson S., Casanova F., and Maddison P. J. "Effects of highintensity resistance training in patients with rheumatoid arthritis: a randomized controlled trial ,"Arthritis Care and Research 2009; 61(12):1726-1734.

12. 12. Grøn K, Ornbjerg L, Heftland M, Aslam $\mathrm{F}$, Khan N, Jacobs J, et al. The association of fatigue, comorbidity burden, disease activity, disability and gross domestic product in patients with rheumatoid arthritis: results from 34 countries participating in the Quest-RA program. Clin Exp Rheumatol 2014; 32:869-77

13. Katz, P., Margaretten, M., Gregorich, S., Trupin, L. Physical Activity to Reduce Fatigue in Rheumatoid Arthritis: A Randomized Controlled Trial. Arthritis Care \& Research 2017; 70(1): 1-10.

14. Hurkmans, E. J., de Gucht, V., Maes, S., Peeters, A. J., Ronday, H. K., \& Vlieland, T. P. V. Promoting physical activity in patients with rheumatoid arthritis: rheumatologists' and health professionals' practice and educational needs. Clinical Rheumatology 2011; 30(12): 1603-1609.

15. Verhoeven, F., Tordi, N., Prati, C., Demougeot, C., Mougin, F., Wendling, D. Physical activity in patients with rheumatoid arthritis. Joint Bone Spine 2016; 83: 265-270.

16. Sandberg, M.E., Wedrén, S., Klareskog, L., et al. Patients with regular physical activity before onset of rheumatoid arthritis present with milder disease. Ann Rheum Dis 2014; 73: 1541-1544.

17. Cerhan, J.R., Saag, K.G., Criswell, L.A., et al. Blood transfusion, alcohol use, and anthropometric risk factors for rheumatoid arthritis in older women. J Rheumatol 2002; 29: 246-254.

18. Di Giuseppe, D., Bottai, M., Askling, J., et al. Physical activity and risk of rheumatoid arthritis in women: a population-based prospective study. Arthritis Res Ther 2015; 17: 40.

19. Kelley, G.A., Kelley, K.S., Hootman, J.M. Effects of exercise on depression in adults with arthritis: a systematic review with meta-analysis of randomized con-trolled trials. Arthritis Res Ther 2015; 17:21

20. Sandoo A, Veldhuijzen van Zanten JJ, Metsios GS, Carroll D, Kitas GD. Vascular function and morphology in rheumatoid arthritis: a systematic review. Rheumatology (Oxford). 2011; 50(11): 2125-2139.

21. de Jong Z, Munneke $M, Z$ winderman $A H$, et al. Is a long-term high-intensity exercise program effective and safe in patients with rheumatoid arthritis? Results of a randomized controlled trial. Arthritis Rheum 2003; 48(9): 2415-2424.

22. Baillet $A$, Vaillant $M$, Guinot $M$, et al. Efficacy of resistance exercises in rheumatoid arthritis: meta-analysis of randomized controlled trials. Rheumatology (Oxford) 2012; 51(3): 519-527.

23. Sharif K, Watad A, Bragazzi NL, Lichtbroun M, Amital $\mathrm{H}$, Shoenfeld $\mathrm{Y}$. Physical activity and autoimmune diseases: Get moving and manage the disease. Autoimmunity Reviews. 2018; 17(1): 53-72.

24. Metsios, G. \& Kitas, G. Physical activity, exercise and rheumatoid arthritis: Effectiveness, mechanisms and implementation. Best Practice \& Research Clinical Rheumatology 2018; 32: 669-682.

25. Yamane, Taro. Statistics, An Introductory Analysis, 2nd Ed., New York: Harper and Row. 1967. 